\title{
The predictive significance of CD20 expression in B-cell lymphomas
}

Veronika Kloboves Prevodnik ${ }^{1 *}$, Jaka Lavrenčak', Mateja Horvat $^{2}$ and Barbara Jezeršek Novakovič ${ }^{3}$

\begin{abstract}
Background: In our recent study, we determined the cut-off value of CD20 expression at the level of 25000 molecules of equivalent soluble fluorochrome (MESF) to be the predictor of response to rituximab containing treatment in patients with B-cell lymphomas. In 17.5\% of patients, who had the level of CD20 expression below the cut-off value, the response to rituximab containing treatment was significantly worse than in the rest of the patients with the level of CD20 expression above the cut-off value. The proportion of patients with low CD20 expression who might not benefit from rituximab containing treatment was not necessarily representative. Therefore the aim of this study was to quantify the CD20 expression in a larger series of patients with B-cell lymphomas which might allow us to determine more reliably the proportion of patients with the CD20 expression below the cut-off.
\end{abstract}

Methods: Cytological samples of 64 diffuse large B-cell lymphomas (DLBCL), 56 follicular lymphomas (FL), 31 chronic lymphocytic leukemias (CLL), 34 mantle cell lymphomas (MCL), 18 marginal zone lymphomas (MZL) and 15 B-cell lymphomas unclassified were analyzed for CD20 expression by quantitative four-color flow cytometric measurements using FACSCalibur flow cytometer (BD Biosciences).

Results: The range of CD20 expression in different B-cell lymphomas was very broad, varying from 2737 to 115623 MESF in CLL and 3549 to 679577 MESF in DLBCL. However, when we compared the CD20 expression in the groups of patients with DLBCL, FL, MCL, MZL, CLL and B-cell lymphomas unclassified, it was found to be significantly lower $(p=0.002)$ only in CLL but did not significantly differ in other lymphoma types $(p=N S)$. Fifty-three out of 218 (24.3\%) patients with B-cell lymphomas had the CD20 expression below the cut-off value.

Conclusions: The CD20 expression in CLL is significantly lower than in most histological types of mature B-cell lymphomas in which it appears to be comparable. Approximately $25 \%$ of B-cell lymphoma patients have the CD20 expression below the cut-off value showing that the low CD20 expression might be more common than presumed from our previous study.

\section{Background}

The study of CD20 expression (cluster of differentiation antigens) in lymphoma cells is vital not only to establish an accurate diagnosis but also to prepare an appropriate plan of treatment with biological drugs [1,2]. As rituximab is a biological drug most frequently used in the treatment of B-cell lymphomas, the study of CD20 expression is becoming increasingly important, in particular in the light of most effective treatment planning and appropriate following-up of response to treatment. Even so, only few studies on CD20 expression in the patients with different histology types of B-cell lymphoma have been so far

\footnotetext{
* Correspondence: vkloboves@onko-i.si

'Institute of Oncology, Department of Cytopathology, Ljubljana, Slovenia Full list of author information is available at the end of the article
}

performed. In these few studies, it has been confirmed that, in the majority of B-cell lymphomas, the CD20 antigen is expressed on the surface of neoplastic cells; however, the intensity of CD20 expression varies by the type of lymphoma and by the differentiation of lymphoma $\mathrm{B}$-cells. It is therefore assumed that the CD20 expression is low in the cells of B-cell chronic lymphocytic leukemia (CLL), while it is most intense in the cells of diffuse large B-cell lymphoma (DLBCL) and of hairy cell leukemia [3-5]; by contrast, it is only exceptionally aberrantly expressed in the cells of multiple myeloma [6,7].

In addition, only sporadic studies have been investigating whether the level of CD20 expression is related to the response to treatment with rituximab. The results of two studies concluded recently showed indeed that the

\section{() Biomed Central}


clinical outcome of patients with low CD20 expression was worse than that of patients with high CD20 expression $[8,9]$. One of these studies was performed in our laboratory. In this study, we determined the cut-off value of CD20 expression at the level of 25000 molecules of equivalent soluble fluorochrome (MESF) to be the predictor of response to rituximab containing treatment in the patients with B-cell lymphomas. Namely, the patients with low CD20 expression responded to rituxmab containing treatment poorly or not at all compared to patients with the CD20 expression above the cut-off level. We also observed that slightly less than one fifth of patients (17.5\%) with B-cell lymphomas had the CD20 expression below the cut-off value [9].

The purposes of the present study were firstly to assess the level of CD20 expression in B-cell lymphomas most frequently occurring in Slovenia where the incidence of B-cell lymphoma is similar to that in Western Europe and North America [10,11] and secondly to determine the proportion of patients with the CD20 expression below the cut-off value of 25000 MESF in a larger series of patients.

\section{Methods}

Two hundred and eighteen patients diagnosed and treated for primary or recurrent lymphoma at the Institute of Oncology Ljubljana, Slovenia between 2003 and 2007 were included in the study. By the time of cytological sampling, none of the patients had been treated with rituximab. In all patients, the primary or recurrent lymphoma had been suspected clinically. Cytological examination with flow cytometric immunophenotyping (FCI) was performed to make or confirm the diagnosis of lymphoma. The cytological diagnosis was further verified by excisional biopsy and histological examination in most cases. Only exceptionally, when the excisional biopsy could not be performed, the cytological diagnosis was validated through clinical follow-up. Among 218 patients included in the study, 64 (29.4\%) were diagnosed with DLBCL, 56 (25.7\%) follicular lymphoma (FL), 31 (14.2\%) CLL, 18 (8.2\%) marginal zone lymphoma (MZL), 34 (15.6\%) mantle cell lymphoma (MCL) and 15 (6.9\%) with B-cell lymphoma unclassified.

\section{Cytological examination and $\mathrm{FCl}$}

For 218 patients included in our study, 192 lymph node fine needle aspiration biopsies (FNAB), 14 effusions, 7 cerebrospinal fluids, 1 bronchoalveolar lavages (BAL) and 4 peripheral blood samples were obtained for cytological examination and FCI. From each sample, 2 smears were prepared for microscopic examination and stained according to Giemsa and Papanicolaou method. Cells of the rest of the sample were suspended in cell media (4.5\% bovine serum albumine, $0.45 \%$ EDTA in phosphate buffer solution with $50 \mathrm{IE} / \mathrm{ml}$ of penicillin) to prepare cell suspension for FCI. The absolute number of cells in total volume of cell suspension was determined in a Neubauer improved bright-line chamber. Samples for four-color FCI were prepared according to the protocol adopted for cytological samples at the Institute of Oncology, Ljubljana, Slovenia [12]. Antibodies by BD Biosciences were mostly applied, except in case of the antiCD52 antibody which was purchased from Serotec Ltd (Table 1). The samples were first filtered through $50 \mu \mathrm{m}$ pore filter. Then, 200000 cells and $1.5 \mathrm{ml}$ buffer (Cell Wash -BD Biosciences) were put in each test tube, mixed and centrifuged for 5 minutes at 1500 turns per minute. The supernatant was discarded and 3 or $5 \mu \mathrm{l}$ of antibodies were added according to the antibody panel presented in Table 1 . The samples were then mixed and incubated in dark for 20 minutes. After incubation, $1.5 \mathrm{ml}$ buffer (Cell Wash - BD Biosciences) was added to the sample, mixed and centrifuged for 5 minutes at 1500 turns per minute. The supernatant was discarded and $300 \mu \mathrm{l}$ of buffer (Cell Wash -BD Biosciences) was added [12]. The samples were measured with four-color flow-cytometer FACSCalibur (BD Biosciences). CellQuest software (BD Biosciences) was used for the acquisition and analysis of the results. In each test tube, we acquired 20000 of CD45 or CD19 positive events depending on antibody panel presented in Table 1. For the analysis of the results, combined side scatter and surface marker (CD45 or CD19) gating was used.

\section{Flow cytometric quantification of CD20 expression}

For the quantification of the CD20 expression, the SPHERO Rainbow Calibration beads (Spherotech, Illinois, USA) were employed. The SPHERO Rainbow Calibration beads have been daily used in our laboratory for monitoring the performance status of flow-cytometer since 2001. Since these beads and the samples included in our study have been always acquired applying equal flow-cytometric settings, we could use the beads for the quantification of CD20 expression. The PMT Linearity QC Record software (Spherotech, Illinois, USA) was applied to determine the relative level of CD20 expression in MESF [13].

\section{Statistical analysis}

Because the measurement variables did not meet the normality assumption of an anova, we used the nonparametric tests. Median, interquartile range and range between minimal and maximal variable were used for the description of CD20 expression. Kruskal Wallis and Mann Whitney tests were used to assess the difference in CD20 expression between the groups of patients with different histological types of B-cell lymphomas. 
Table 1 Standard antibody panel used in the diagnostics of B-cell lymphomas

\begin{tabular}{|c|c|c|c|c|c|c|c|c|}
\hline & FITC & & PE & & PerCP/F & -Cy5.5 & APC & \\
\hline Test tube & mAbs & $\begin{array}{l}\text { Volume } \\
(\mu \mathrm{l})\end{array}$ & mAbs & $\begin{array}{l}\text { Volume } \\
(\mu \mathrm{l})\end{array}$ & mAbs & Volume $(\mu \mathrm{l})$ & mAbs & $\begin{array}{l}\text { Volume } \\
(\mu \mathrm{l})\end{array}$ \\
\hline $1^{* *}$ & $\mathrm{CD}^{*}$ & 5 & CD19* & 5 & $\mathrm{CD}_{4} 5^{*}$ & 5 & CD20 & 3 \\
\hline $2^{* *}$ & $\gamma 1$-FITC & 5 & $\gamma 1-P E$ & 5 & CD19 & 5 & $\gamma 1-\mathrm{APC}$ & 3 \\
\hline $3^{* *}$ & Kappa* & 5 & Lambda* & 5 & CD19* & 5 & CD10 & 3 \\
\hline $4^{* *}$ & $\mathrm{FMC7}^{*}$ & 5 & CD23* & 5 & CD19* & 5 & CD5 & 3 \\
\hline 5 & CD52 & 3 & CD11 & 5 & CD19 & 5 & CD38 & 3 \\
\hline 6 & $\mathrm{CD}^{*}{ }^{*}$ & 5 & $\mathrm{CD} 8^{*}$ & 5 & $\mathrm{CD}^{*}$ & 5 & CD2 & 3 \\
\hline
\end{tabular}

mAbs monoclonal antibodies, FITC fluorescein isothiocyanate, PE phycoerythrin, PerCP peridinin chlorophyll protein, PerCP-Cy5.5 peridinin chlorophyll proteinCy5.5, APC-allophycocyanin, *BD Oncomark Reagents, ** when the samples were poorly cellular only test tubes 1-4 were applied.

The research was approved by National Ethic Committee and was performed in compliance with the Helsinki declaration.

\section{Results}

The CD20 expression in different B-cell lymphomas is presented in Table 2. The highest median CD20 expression was observed in the patients with DLBCL and the lowest in the patients with CLL. The range of CD20 expression in different B-cell lymphomas was wide, varying from 2737 to 115623 MESF in CLL and 3549 to 679577 MESF in DLBCL.

When the CD20 expressions in DLBCL, FL, MCL, MZL, CLL and B-cell lymphomas unclassified were compared, it was found to be significantly lower ( $\mathrm{p}=$ 0.002) only in CLL (Figure 1), but not significantly different from other lymphoma types $(\mathrm{p}=\mathrm{NS})$.

In our study population, $24.3 \%$ of patients had the level of CD20 expression below the cut-off value of 25000 MESF. The highest percentage (74.2\%) of patients with the level of CD20 expression below the cut-off value was noted in the group of patients with CLL while the lowest (7.1\%) was observed in the group of patients with FL (Table 3, Figure 2). Table 3 also presents the number and the percentage of patients with the CD20 expression below the cut-off value in the present study compared to the results obtained in our previous study (8)

\section{Discussion}

In the literature, there are only few data on the level of CD20 expression in different types of B-cell lymphoma. From the collected data, it may be concluded that the types of B-cell lymphoma differ from each other by CD20 expression; however, there is no clear evidence on the range of these differences and the variability of CD20 expression within each histological type of B-cell lymphoma.

Ginaldi et al. were the first to report that the level of $\mathrm{CD} 20$ expression in the patients with the leukemic form of B-cell lymphoma is significantly the lowest in CLL and the highest in hairy cell leukemia. No statistically significant difference was observed between the CD20 expressions in B-cell prolymphocytic leukemia, splenic MZL and MCL [3]. Similar results were reported by Huh et al. and Olejniczak et al. who compared the CD20 expressions in CLL, small B-cell lymphocytic lymphoma, acute lymphoblastic leukemia, hairy cell leukemia, DLBCL, FL, splenic MZL, and MCL $[4,5]$. Our results are consistent with those obtained by Ginaldi, Huh and Olejniczak, as they also show that the CD20 expression in the neoplastic cells of CLL is statistically significantly lower than that in other B-cell lymphomas included in our study $(\mathrm{p}=0.002)$. We did not observe any statistically significant differences between the CD20 expressions in DLBCL, FL, MCL, MZL and B-cell lymphomas unclassified $(p=N S)$. Though there was no

Table 2 CD20 expression in different histological types of B-cell lymphomas

\begin{tabular}{lccc}
\hline Histological type of B-cell lymphoma (N) & \multicolumn{3}{c}{ CD20 expression (MESF) } \\
& Median & Range & IQR \\
\hline DLBCL (64) & 82726 & $3549-679577$ & $28234-144721$ \\
FL (56) & 72011 & $8460-445755$ & $48179-123202$ \\
MCL (34) & 66375 & $8826-423799$ & $39725-99915$ \\
MZL (18) & 62305 & $3615-207034$ & $31359-91178$ \\
CLL (31) & 14064 & $2737-115623$ & $8275-26855$ \\
NOS (15) & 33871 & $8106-349091$ & $19648-153972$ \\
\hline
\end{tabular}

MESF...molecules of soluble fluorochrome, N...number of patients, IQR...interquartile range, DLBCL...diffuse large B-cell lymphoma, FL...follicular lymphoma, MCL... mantle cell lymphoma, MZL...marginal zone lymphoma, CLL...chronic lymphocytic leukemia, NOS...B-cell lymphoma unclassified. 


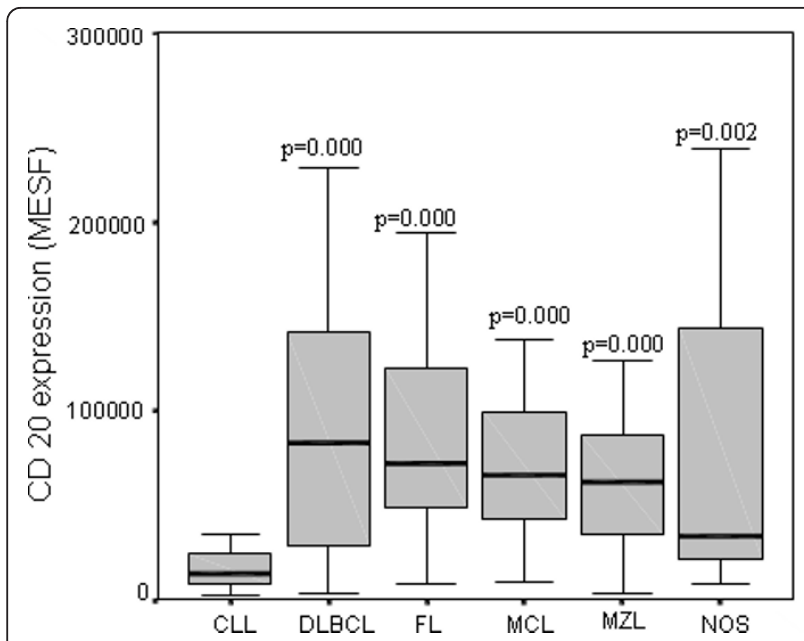

Figure 1 CD20 expression in different B-cell lymphomas. MESF....molecules of soluble fluorochrome, CLL...chronic lymphocytic leukemia, DLBCL...diffuse large B-cell lymphoma, FL...follicular lymphoma, MCL...mantle cell lymphoma, MZL...marginal zone lymphoma, NOS...B-cell lymphomas unclassified, NS...not significant.

statistically significant difference in the CD20 expressions in DLBCL, FL, MCL, MZL and B-cell lymphomas unclassified, the results of our study showed that the CD20 expressions varied significantly within different types of B-cell lymphomas. This may explain why the response to treatment with rituximab of the patients with the same type of lymphoma is so diverse.

Despite numerous clinical and preclinical studies on rituximab, the treatment with this drug has not outgrown its empirical use - we can confirm its efficacy only in the patients in whom the CD20 expression was determined in lymphoma cells, but we are not sure whether the level of surface CD20 expression may be a predictive factor, identifying the patients in whom the treatment with rituximab would be efficient and those in whom the use of this drug would be inefficient [14-16]. Results of two similar studies, investigating whether the level of CD20 expression is related to the response to treatment with rituximab, have been recently published. Johnson et al. have demonstrated that the CD20 expression and response to treatment with rituximab are connected. In the group of 272 patients with DLBCL treated with chemotherapy or immunotherapy with rituximab, the survival of patients with low CD20 expression was worse than that of patients with high CD20 expression [9]. The results of our most recent study are comparable to those of Johnson's study. In the study performed on 114 patients with different histological types of B-cell lymphoma, we found a correlation between the level of CD20 expression and response to treatment with rituximab. We also determined the cut-off value of CD20 expression at the level of 25000 molecules of equivalent soluble fluorochrome (MESF) to be the predictor of response to rituximab containing treatment in the patients with B-cell lymphomas. This assumption was supported by our findings that the patients with the level of CD20 expression above the cut-off value had a significantly longer overall survival $(\mathrm{p}=0.038)$ and a significantly higher overall response rate $(\mathrm{p}<0.001)$ than the patients with the level of CD20 expression below the cut-off value. Yet, we observed no significant difference in the response duration between the two groups. By means of the determined cut-off level of CD20 expression we estimated that approximately one fifth of the B-cell lymphoma patients with low CD20 expression will not respond to rituximab containing treatment at all or will not respond optimally [8].

Because this presumption was based on the results of the study including only a smaller series of patients, the proportion of patients with the CD20 expression below the cut-off value might not be necessarily representative. Namely, in the reported study, some B-cell lymphoma groups consisted of only few patients, for example of only 2 patients in the MZL group and of only 5 patients in the CLL group. The reliability of the proportion of patients having the CD20 expression

Table 3 Patients with the CD20 expression below the cut-off value

\begin{tabular}{|c|c|c|c|c|c|}
\hline $\begin{array}{l}\text { Histological } \\
\text { type of } \\
\text { B-cell } \\
\text { lymphoma }\end{array}$ & $\begin{array}{l}\text { Number of patients } \\
\text { below the cut-off value/ } \\
\text { Total number of patients }\end{array}$ & $\begin{array}{l}\% \text { of patients } \\
\text { below the } \\
\text { cut-off value }\end{array}$ & $\begin{array}{l}\text { Number of patients } \\
\text { below the cut-off value/ } \\
\text { Total number of patients }\end{array}$ & $\begin{array}{l}\% \text { of patients } \\
\text { below the } \\
\text { cut-off value }\end{array}$ & $\begin{array}{l}\text { Percentual difference in the } \\
\text { proportion of patients below the } \\
\text { cut-off value between the two } \\
\text { studies }\end{array}$ \\
\hline$\overline{D L B C L}$ & $11 / 64$ & 17.2 & $6 / 42$ & 14.3 & 2.9 \\
\hline $\mathrm{FL}$ & $4 / 56$ & 7.1 & $2 / 30$ & 6.7 & 0.4 \\
\hline CLL & $23 / 31$ & 74.2 & $4 / 5$ & 80.0 & 5.8 \\
\hline $\mathrm{MCL}$ & $6 / 34$ & 17.6 & $3 / 20$ & 15.0 & 2.6 \\
\hline$M Z L$ & $4 / 18$ & 22.2 & $0 / 2$ & 0 & 22.2 \\
\hline NOS & 5/15 & 33.3 & $5 / 15$ & 33.3 & 0 \\
\hline Total & $53 / 218$ & 24.3 & $20 / 114$ & 17.5 & 6.8 \\
\hline
\end{tabular}

DLBCL...diffuse large B-cell lymphoma, FL...follicular lymphoma, CLL chronic lympocytic leukemia, MCL...mantle cell lymphoma, MZL...marginal zone lymphoma, NOS...B- cell lymphoma unclassified, text in bold...the results has been published in our previous study (M. Horvat et al. [8]). 


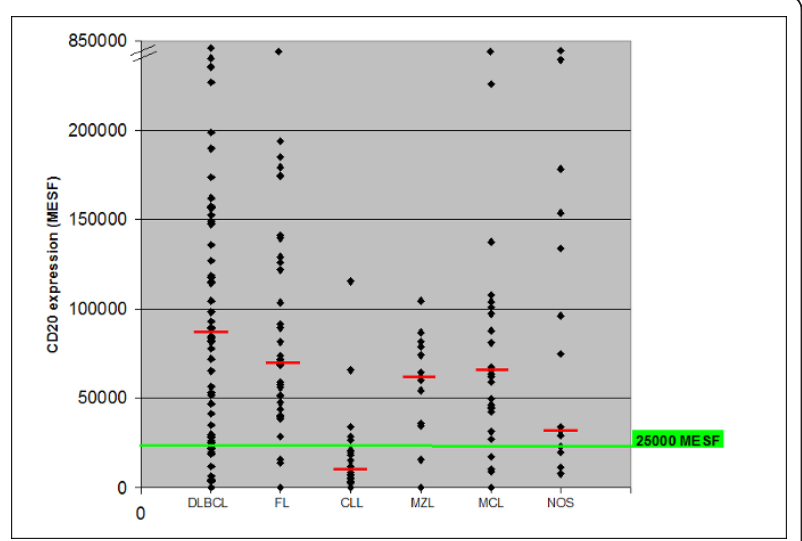

Figure 2 CD 20 expression in B-cell lymphomas according to the cut-off value. MESF...molecules of soluble fluorochrome, DLBCL...diffuse large B-cell lymphoma, FL...follicular lymphoma, CLL... chronic lympocytic leukemia, MCL...mantle cell lymphoma, MZL... marginal zone lymphoma, NOS...B- cell lymphoma unclassified, -... median values of CD 20 expression.

below the cut-off value in these two groups might therefore be questionable.

Having expanded the study population, we detected that almost $25 \%$ of B-cell lymphoma patients had the CD20 expression below the cut-off value of 25000 MESF. This proportion is higher than the $17.5 \%$ reported in our previous study. Among the patients with the CD20 expression below the cut-off value, we found prevailingly the patients with CLL (74.2\%) and most infrequently the patients with FL (7.1\%). This distribution of low CD20 expression is for the most part in concordance with our previous findings [8]. However, the proportion of patients with the CD20 expression below the cut-off value varied in different B-cell lymphoma groups when we expanded the study population. It increased substantially in MZL (for as much as $22.2 \%$ ) and decreased in CLL patient group (for 5.8\%). In the groups of patients with DLBCL, FL and MCL, on the other hand, we observed only a slight increase in the percentage of patients having the CD20 expression below the cut-off limit - the increase being between 0.4 to $2.9 \%$. We believe, that these changes are attributable to the altered number of patients belonging to each of the B-cell lymphoma groups.

The results of our study indicate that the level of CD20 expression is an important predictive factor for the response to rituximab containing treatment. Still, we believe that further studies on the intensity of CD20 expression should be carried out in a homogeneous population of patients with identical histological types of B-cell lymphoma.

\section{Conclusions}

CD20 expression in CLL is significantly lower than in most histological types of mature B-cell lymphomas in which it appears to be very comparable. Almost $25 \%$ of B-cell lymphoma patients have the CD20 expression below the cut-off value of 25000 MESF which was proposed to be the predictor of response to treatment with rituximab. This proportion (24.3\%) is higher than the one reported in our previous study (17.5\%). Further studies are needed for the patients with every histological type of B-cell lymphoma to confirm our observations that the patients with low CD20 expression respond to rituximab containing treatment poorly or not at all.

\section{Author details}

'Institute of Oncology, Department of Cytopathology, Ljubljana, Slovenia. ${ }^{2}$ Bayer d.o.o., Ljubljana, Slovenia. ${ }^{3}$ Institute of Oncology, Department of Medical Oncology, Ljubljana, Slovenia.

\section{Authors' contributions}

VKP designed the study and wrote the manuscript. JL carried out the flow cytometric data acquisition and analysis. MH performed statistical analysis and assisted in flow cytometric data analysis. BJN participated in clinical discussion and reviewed the manuscript. All authors read and approved the final manuscript.

\section{Competing interests}

The authors declare that they have no competing interests.

Received: 11 February 2011 Accepted: 12 April 2011

Published: 12 April 2011

\section{References}

1. Jezeršek Novaković B, Kotnik V, Južnič Šetina T, Vovk M, Novaković S: Testing of mechanisms of action of $\mathrm{R}$ and clinical results in high-risk patients with aggressive CD20+ lymphoma. Radiol Oncol 2007, 41(1):23-32.

2. Cheson BD, Leonard JP: Monoclonal antibody therapy for B-cell nonHodgkin's lymphoma - Review. N Engl J Med 2008, 359(6):613-26.

3. Ginaldi L, De Martinis M, Matutes E, Farahat N, Morilla R, Catovsky D: Levels of expression of CD19 and CD20 in chronic B cell leukaemias. J Clin Pathol 1998, 51(5):364-9.

4. Olejniczak SH, Stewart CC, Donohue K, Czuczman MS: A quantitative exploration of surface antigen expression in common B-cell malignancies using flow cytometry. Immunol Invest 2006, 35(1):93-114.

5. Huh YO, Keating MJ, Saffer HL, Jilani I, Lerner S, Albitar M: Higher levels of surface CD20 expression on circulating lymphocytes compared with bone marrow and lymph nodes in B-cell chronic lymphocytic leukemia. Am J Clin Pathol 2001, 116(3):437-43.

6. Hennessy BT, Hanrahan EO, Daly PA: Non-Hodgkin lymphoma: an update. Lancet Oncol 2004, 5(6):341-53.

7. Lin P, Owens R, Tricot G, Wilson CS: Flow cytometric immunophenotypic analysis of 306 cases of multiple myeloma. Am J Clin Pathos 2004, 121:482-88.

8. Horvat M, Kloboves Prevodnik V, Lavrenčak J, Jezeršek Novakovič B: Predictive significance of the cut-off value of CD20 expression in patients with B-cell lymphoma. Oncol Rep 2010, 24(4):1101-7.

9. Johnson NA, Boyle M, Bashashati A, Leach S, Brooks-Wilson A, Sehn LH, et al: Diffuse large $B$ cell lymphoma: reduced CD20 expression is associated with an inferior survival. Blood 2009, 113(16):3773-80.

10. Primic-Žakelj M: Epidemiologija in register raka v Sloveniji, Incidenca raka v Sloveniji 2006. Ljubljana: Onkološki inštitut; 2009.

11. Swerdlow AJ: Epidemiology of Hodgkin's disease and non-Hodgkin's lymphoma. Eur J Nucl Med Mol Imaging 2003, 30(Suppl 1):S3-12.

12. Kloboves-Prevodnik V, Fležar M, Pohar-Marinšek Ž: Improved method for flow cytometric immunophenotyping of FNAB samples (abstract). XXII ISAC international congress Montpellier: International society for analytical cytology; 2004, 14 
13. Schwartz A, Gaigalas AK, Wang L, Marti GE, Vogt RF, Fernandez-Repollet E: Formalization of the MESF unit of fluorescence intensity. Cytometry part $B$ (Clinical Cytometrey) 2004, 57B:1-6.

14. Marcus R, Hagenbeek A: The therapeutic use of $R$ in non-Hodgkin's lymphoma. Eur J Haematol Suppl 2007, 67:5-14.

15. Fanale MA, Younes A: Monoclonal antibodies in the treatment of nonHodgkin lymphoma. Drugs 2007, 67(3):333-50.

16. Hagemeister F: Rituximab for the treatment of non-Hodgkin's lymphoma and chronic lymphocytic leukemia. Drugs 2010, 70(3):261-72.

doi:10.1186/1746-1596-6-33

Cite this article as: Prevodnik et al.: The predictive significance of CD20 expression in B-cell lymphomas. Diagnostic Pathology 2011 6:33.

Submit your next manuscript to BioMed Central and take full advantage of:

- Convenient online submission

- Thorough peer review

- No space constraints or color figure charges

- Immediate publication on acceptance

- Inclusion in PubMed, CAS, Scopus and Google Scholar

- Research which is freely available for redistribution

Submit your manuscript at www.biomedcentral.com/submit 